\title{
Note on Japanese Names and the Romanization of Japanese Language
}

In this book, Japanese proper names are denoted with the family ("last") name preceding the given ("first") name. The modified Hepburn system (Hebon-shiki) is used to romanize the Japanese language. Accordingly, long vowels are marked with macrons $(\overline{\mathrm{a}}, \overline{\mathrm{e}}, \overline{\mathrm{i}}, \overline{\mathrm{o}}, \overline{\mathrm{u}})$, with the exception of the transcription and quotation of actual speech, in which the lengthening of vowels is marked with additional vowels (e.g., "aa" instead of " $\vec{a}$ "). 
This page intentionally left blank 